\title{
Strengths and Weaknesses of Postmodern Legacy on Development Studies: a case study from an NGO in China
}

\author{
Sun Guoyuan \\ Dept. of Social Work, \\ University of Yunnan Finance and Economics, Kunming, Yunnan, China \\ guoyuansun@foxmail.com
}

\begin{abstract}
This paper tries to analyse the roots of post-development theories, first in modern theories and then, post-modern theories. It also provides an in-depth analysis of the strengths and weaknesses of post-development by an empirical example from an NGO in China. Post-development theory is a powerful tool to re-examine the questions of whose 'development' and whether it is relevant for the social majority. The grassroots initiatives and practice are also valuable raised by the post-development theory. However, practice is even more complicated, full of different actors, power relations and other factors. Post-development theory cannot replace all other development theories; otherwise, it will also become a hegemonic discourse itself. Also, development, as a term and practice, is still fluid and opens to the redefinition and the complete abandonment is not reasonable.
\end{abstract}

Keywords - development; postmodern theory; China

\section{INTRODUCTION}

Postmodern theories have significantly influenced the field of development studies, attacking development as, fundamentally, a form of social control over the developing world and its people. Some post-development thinkers have even proposed a dismissal of development. This paper argues that post-development theory is a powerful theory for rethinking development discourse and practice from the perspective of power relations. At the same time however, in practice, there are more factors that need to be considered and other theories that should be utilized to analyze reality and resolve practical development problems.

This paper attempts to analyze the strengths and weaknesses of post-development theories. First, it will explore the modern theories that serve as the points of departure for postmodern theory, followed by a discussion of the postmodern critique itself. Then, it will elaborate post-development's strengths and weaknesses using empirical examples from the field.

\section{WHAT IS POSTMODERN THEORY?}

Basically, postmodern theory is a theory that criticizes modernity and modern theory. Modern theory is related with scientific and technological improvements, meta-theory, universal knowledge and the dichotomy between subject and object, which have been challenged by postmodernists.
Hence, in this section, this paper will examine the key characteristics of modernity and modern theories. Postmodern theory will then be discussed in depth afterwards.

\section{A. Modernity and modern theory}

Modern theory originated from the Enlightenment era, which draws on ideas from the classical era and Judaeo-Christian era. Trevor Parfitt analyzed how modern theories have been brought about in retrospect of the classical era and then dominant Judaeo-Christian concept era. During the classical era, Greek philosophy regarded nature as a divine integrity that included human beings, gods and other existences, and the rules of nature allowed the world to exist and develop. However, when so-called Western world entered into the Judaeo-Christian era, God was separated from nature and regarded as the creator of nature, human being and the whole cosmos. Therefore, human beings knew the world and manage nature only through the God. Gradually philosophers debated on whether human beings could obtain knowledge, whether reality could be discovered by human beings, and if so, to what extent, the knowledge of human beings was true about reality. The significant historic event was that the so-called modern philosophers thought it was the human beings' rationality and reason that allowed them know the world and reality and, moreover, made them capable of exploiting nature. At that time, human beings eventually separated from nature and became the subject in a world where nature was the object (Partiff, 2002: 12-28).

It is suggested that the key changes, which gave rise to theories of modernity, include two characteristics. First, nature can be discovered through the reason and rationality of human beings who have autonomy. Second, knowledge can be obtained by human beings.

Hence, modern theory is regarded with three elements. Firstly, it is related with rapid scientific and technological improvements which are regarded as tools for the exploitation of nature and for better life and better societies. Secondly, modern theories usually are meta-theories which are highly generalized and structural. They are of 'social totalities and their parts with nothing unexplained or left to change' (Peet, 1999: 123). Rostow's pro-capitalist theory of the stages of growth is an example of a meta-theory and neo-liberal theory is another. Thirdly, scientific knowledge, obtained through 
individual reason, rationality and empirical research, is regarded as the universal truth, while discounting other diverse forms of knowledge. Fourthly, modern theory results in subject-objects relationships, the former being those people with power, Western people, etc and the latter nature, the oppressed etc.

\section{B. Critiques on modern theories from postmodern theories}

Firstly, postmodernists challenge the foundationalism of modern theory. In modern theory, the true statements, arguments and beliefs are grounded. As Agnes Heller argues, there are some final grounds in modern theories that cannot be grounded further. However, if the final grounds have been shaken, the theory seems ungrounded inevitably as well (Heller in Partiff, 2002: 23-24). Since modern theories tend to apply a conceptual framework to analyze the research, they are criticized by postmodernists for using frameworks that are too narrow and neglect or marginalize some truth of the reality. Furthermore, the nature of the relationship between reason and reality is questionable, which poses a central problem for modern theories (Louis Dupré in Partiff, 2002:25). Jacques Derrida stated that knowledge is linguistically mediated and historically specific reality (in Peet 1999:126). Nietzsche also argued 'against positivism..."there are only facts"....no facts are...only interpretations' (in Partiff, 2002:26). Nietzsche's intention, summarized by Partiff (2002) is that the 'true' knowledge is defined by the most powerful. Foucault held the same position with Nietzsche:

\footnotetext{
Truth is not outside of power....Each society has its own regime of truth, its general politics of truth.... There is a combat for the truth, or at least around the truth, as long as we understand by the truth not those true things which are waiting to be discovered but rather the ensemble of rules according to which we distinguish the true from the false, and attach special effects of power to 'the truth.'(Foucault in Peet, 1999:130)
}

Secondly, 'modern reason,' the foundation of the modern theories, has been criticized because 'reason' is not universal but historic and regional in the postmodernist perspective. Furthermore, postmodernists argue 'modern reason' has become a social control. The most visible social control is by disciplinary institutions, including schools. Moreover, rationalized socialization is the most disguised forms. The most subtle social control is rational self-discipline (Peet 1999:126).

Thirdly, postmodernists criticize modern theories' creation of the subject-object relationship. Nature, as an object, has been exploited by human beings, the subject, with the aim of emancipation of human beings. Meanwhile, under the same name of emancipation, the social majority, as an object, have been exploited by social 'minorities'. In some modern theories, Europeans are claimed to possess the highest level of reasoning capabilities while people in other areas are not as advanced as their counterparts in Europe, notions which often have been used to justify 'development' and colonization.

Fourthly, postmodernists argue that history is a contingent and spontaneously historic event rather than a goal for societal development (Peet 1999, Partiff 2002). Peet summarized that postmodernists 'saw events erupting spontaneously from a far more anarchic world than structuralism had suggested' (1999:124). Hence, they do not believe modern theories where history development has a universal model and human emancipation can be achieved in modern development.

In sum, postmodernists have attacked the modernists' foundational understandings of reason, truth and its accuracy. The foundation of the truth has been doubted and truth does not exist but rather power. Postmodern theories have been introduced into development studies by researchers such as Arturo Escobar and as a consequence, significantly changed the landscape of the discipline.

\section{POSTMODERN THEORIES ON DEVELOPMENT STUDIES}

Post-development theorists apply postmodern theory on development studies and argue that development, as a discourse, is a social control by unfair power. Development, as a tool of modernization, claims the universal knowledge and Western social progress. Post-development theory challenges the premise of development and advocates an alterative development, alternative to development, etc.

\section{A. Historical context of postmodern theory and development studies}

By looking at the historical evolution of the term, 'development,' it becomes easier to understand why postmodern theories have influenced development studies.

Development, a term used in mainstream research and practice, was originally derived from the colonial era to refer to the development of the British colonies. Development has become a more popular term in the research and development industry since the end of World War II and, specifically, the 1949 Inaugural Address of US President Harry Truman. Since then, development seems to equate to economic development. Industrialization and urbanization have been development's main targets. Since the 1980s, neo-liberal strategies have been adopted by the World Bank and IMF in Latin American and African countries.

In the meantime, there are also oppositions to economically dominant development such as the basic needs development, women in development etc. However, economic development is still the most dominant. From the 1960s to 1990s, witnessing the failure of development, in terms of the increasing disparity of wealthy countries and poor countries, the degradation of the environment, etc, some scholars began to attack the premise of development. The application of postmodern theories to the analysis of the discourse and premise of development is called post-development theories.

\section{B. Post-development theories}

Firstly, development, the term itself, has been analyzed as a discourse with hidden, unfair power relations by post-development thinkers. Escobar is the pioneer researcher who applied the power-knowledge-truth of Foucault in development to analyze the power relations present in development and its history. Escobar (1995) argued that 'development' is a discourse controlled by Western values, such as reasoned knowledge, modern science and technology, and specifically the hegemony of the United States during the Cold War. The Third World is a representation made by development apparatuses since President Harry Truman in his 1949 Inaugural Address. The Western dream has become an 
aspiration around the globe. Development as a sign of progress has been imposed on Third World people.

Escobar followed Foucault's thoughts on how certain representations shape the reality to be imagined and acted upon and argued that the social reality, the underdevelopment and development, is represented by the interactions and imposition from discourse and power, Western power and ideas. Moreover, the discourse of development is decided by a system of growth and modernization. As Escobar mentioned, 'the system of relations establishes a discursive practice that sets the rules of the game; who can speak, from what points of view, with what authority, and according to what criteria of expertise' (1995:41).

Secondly, post-development thinkers challenged the idea of universal knowledge and science, favoring local knowledge instead. The dominant so-called universal knowledge is actually Western knowledge which does not draw from diverse cultures and contexts and destroys traditional community and culture. Local knowledge and science should be heard and applied for grassroots people and communities, in post-development's perspective.

Thirdly, feminism criticized modern theories from a gender perspective combined with an environmental perspective. Modernity, argued by Catherine Scott, is based on an often-idealized version of masculine modernity, which is a 'rational, forward-looking, male-dominated public sphere' (in Hartwick 1999:176). Tradition, nature and the feminine are oppressed for modernization. Women's issues are always ignored by development apparatus. Moreover, when gender issues are brought into development, poor women are constructed as 'Third World' women (Hartwick, 1999).

Carolyn Merchant (1980) argued that the particular worldview of modern science has brought about the death of nature in the name of progress. Development is a Western patriarchal dominance and is, in practice, resisted by women for the nature and their livelihood as well. (Shiva in Hartwick, 1999: 188-189).

\footnotetext{
Indian women have been in the forefront of ecological struggles to conserve forests, land and water. They have challenged the western concept of nature as an object of exploitation and have protected her as Prakriti, the living force that supports life. They have challenged the western concept of economics as production of profits and capital accumulation with their own concept of economics as production of sustenance and needs satisfaction. A science that does not respect nature's needs and a development that does not respect people's needs inevitably threaten survival. (Shiva in Hartwick, 1999:189)
}

Fourthly, post-development thinkers hold the position of anti-metatheory. Following postmodern theories, post-developmentalists argued the law of the world and society cannot be completely obtained through human reason. Escobar attacked universal models, whether neoclassical or Marxist, because they deny peoples' capacities to model their own behavior (in Peet: 1999, 148).

Since there are significant weaknesses in current development, post-developmentalists provided a list of proposals.

Most significantly, rooted in Foucault, followed by Escobar, autonomous, decentralized and local knowledge has been favoured and autonomous grassroots development strategy should take the place of development (in Peet, 1999). For Escobar, development should be dismissed and an alternative to development offered in its place (Escobar, 1995). Social movements are regarded as an open space for oppressed people.

Moreover, others call for a simple life style. Western and modern lifestyle is characterised by overconsumption and high material demands which are the base for capitalism. In pre-capitalist societies, life tends to be simpler materially but, perhaps to some extent, richer spiritually. Mahatma Gandhi, in his The Quest of Simplicity was excerpted in The Post-development Reader, saw the modern world become more like machinery and unjust and hence, appealed that human beings should not be greedy and expect more than they need (1997).

In essence, post-development theory challenges the premise of development, the unfair power relations, the universal knowledge, etc; furthermore, they propose an alterative development, alternative to development, etc. In the next section, the strengths and weaknesses of post-development theory will be examined in the concrete cases from the field.

\section{STRENGTHS AND WEAKNESSES OF POST-DEVELOPMENT} THEORIES ILLUSTRATED WITH A CASE FROM AN NGO IN CHINA

Post-development theories are of critical importance to challenge the premise of modern development and advocate an alternative path from grassroots initiatives and cultures. However, in the practice, post-development theories entail a more comprehensive and practical theories and approaches. Two cases studies from the field have been analyzed to illustrate the strengths and weaknesses of post-development theories.

\section{A. Development in China and its alternative}

China provides us with a specific example through which to examine and understand post-development meanings and values. China is on a path of modernization development, though not imposed by the Western discourse of development. Development has its positive impacts, such as the increase of gross domestic products and the income increase; however, the inequality, imbalances and environment degradation are the other side of development. Against the mainstream development environment in China, there are also alternative development practices which will be examined closely.

\section{B. China development contexts}

The historical contexts of Chinese development are, to some extent, different from those of other developing countries, such as African and Latin American countries (except Cuba). Development in China is dominated by the discourse of modernization but not imposed by Western imperialism or hegemony.

Before 1978, when the implementation of Reform and Opening Policy began, China was not influenced by imperialist and Western hegemony, to some extent, because of the Cold War and the country's communist revolution. Hence, during 1949-1978, Western capitalist or imperialism development discourse and practice were not the case in China.

However, since the establishment of People's Republic 
of China, China has experienced a rapid modernization process intrinsically because of several factors including the Marxist theories on social development and human emancipation, the poor domestic development condition, pressure from the Cold War and threats from the United States. The Chinese Communist Party (CCP) leaders pursued a policy objective called the Four Modernizations, including industrial, agricultural, military and education modernization in 1964 during the meeting of the Chinese National People's Congress.

Since 1978 and the launching of the Reform and Opening Policy, Chinese have witnessed dramatic economic and social development. Deng Xiaoping, the CCP leader during the reform, has a widespread discourse 'Development is an absolute way ( $f a$ zhan shi ying dao li)' which is a typical representation of this period. The policy is a market-oriented strategy, which has been called 'market economy with Chinese characteristics.' The policies on the privatization of education (mainly high schools and universities), health care, housing system and state-owned enterprises (except those in industries essential for national security) have spurred rapid economic development in China. During 1978 and 2006, the average of GDP increased by $9.67 \%$ (Ma, 2007).

These recent trends show that development can bring about some progress especially in the material facet. However, the cost of development cannot be ignored. According to China Human Development Report 2005, there exists a big imbalance between urban and rural areas, regions, sexes, different population groups. For example, urban Human Development Index (HDI) is 0.81 while rural HDI 0.67 because of unequal distribution of incomes. According to World Bank's estimate, 'China's national Gini coefficient for income distribution rose from 0.3 in 1982 to 0.45 in 2002, a 50 percent increase in two decades' (in China Human Development Report 2005). The reformed housing, education and health care have become the new 'three mountains' for Chinese people (Guang Yang, 2007). According to a research by Brockmann et al, during the decade of 1990-2000, life satisfaction in China decreases were seen in both rural population and urban population and in every income group (divided into lowest quartile, $2^{\text {nd }}$ quartile, $3^{\text {rd }}$ quartile and highest quartile). 'The percentage of Chinese who described themselves as very happy plummeted from $28 \%$ in 1990 to $12 \%$ in 2000 ' (2008:388). They argued the reason is skewed income inequality. Meanwhile, the environment has deteriorated and the pollution of the Tai Lake serves as an example. Tai Lake, the third largest freshwater lake and also located in the most prosperous industrial area, is nowadays polluted by the industrial waste, urban sewage and chemical fertilizers. The annual economic losses caused by the pollution were conservatively estimated to reach 5 billion Yuan (Alkire and Deneulin, 2009). Furthermore, traditional cultures and spiritual development in China face a difficult situation because they cannot be transferred into human capacities in modern development.

Currently, development has been a dominant discourse used by the government and enterprise, which can be translated into modernized development. It is also mostly a daily word used by popular mass, because of its internalization through propaganda and the real economic development. However, from the dark side of development, it is questionable whether this 'development' is what the people really desire.

Although China is currently a visible picture of mostly every individual busy and under high pressure making money for a better material life; however, there are still some alternative practices which demonstrate a resurgence of ancient life values with some new meanings and elements.

\section{$C$ The practice of an NPO ABX1 in China}

The background of ABX

ABX, an NGO established in 2001, continues to promote a grassroots alternative development movement to this day in China. ABX:

believes that everyone....has the right and the ability to lead a dignified and sustainable life in harmony with others, with nature, and with the world at large...During the past decade, China has experienced an ever widening rich-poor and urban-rural divide. This gap is exacerbated by the power of globalised commercialisation and consumerism. All over the world this alarming reality is unmistakably illustrated in the everyday life of vulnerable and disadvantaged rural populations; in particular, those who suffer not only from material deprivation, but also from discrimination and marginalisation in their society and culture. $\mathrm{ABX}$ has been very much aware of this development trend. Over the past years, our programme has adopted a strategic approach that is people-centred, environmentally conscious and respectful of local cultures, and which reflects critically on values and practices enshrined in the mainstream development model.( ABX 2006: 2)

It shows that $\mathrm{ABX}$ has a deep reflection on the mainstream modern development model which includes consumerism and materialism and focuses on human-nature relations inter-relations amongst human beings as well as grassroots culture. It is noticed by the author that ABX's discourse of its core work is even not sustainable 'development' but rather the promotion of sustainable 'living' (ABX,2008:4) instead, probably because 'living' is broader than the 'development'. ABX Strategic Plan 2007-2008 stated, 'A non-mainstream image has been built through actual programme and publications' (2008:4).

The approaches of ABX

There are two core primary approaches of ABX. Firstly, the community facilitators are nurtured including individuals, civic groups and community-based groups because it is the local community facilitators who can make the local change happen. The community facilitator can contribute to the self-reliance of the local communities.

The other approach is cultural reflection, which includes reflection on sustainable living, problems of mainstream development paths, and the connection on nature and cultures. It might be the first and only NGO who claimed to use cultural reflection as a primary approach in China. In my understanding, cultural reflection is a critical thinking on mainstream development models from cultural and nature perspective for a sustainable living which is beyond the

\footnotetext{
1 Anonymous
} 
mainstream development worldview.

Concrete programme examples from $\mathrm{ABX}$

The cultural reflection can be seen integrated in the diverse programmes. One example is ABX's youth network building programme, namely youth internship programme (YIP), since 2004. This programme is a platform 'for the urban youth to understand the rural, to reflect the modernization, urbanization and marketization development, to reflect the relations of rural and the urban, the relations of human beings and the nature and to foster the urban-rural interactions' (YIP introduction brochure in Zhao et al, 2009). The programme has recruited more than 200 candidates and supports them to intern in the grassroots organization for one year providing related training to them in the themes of environment and rural development. In the evaluation report, it is found that the programme is a good platform to encourage the youth to reflect on the globalization, modernization and urbanization and unsustainability of the mainstream development. It is the training integrated with the strong cultural reflection on the mainstream development that distinguish this programme from other development training programmes.

Another example is the Community Supported Agriculture (CSA) programme of $\mathrm{ABX}$. Responding to the urban-rural gap, low-profit agriculture and environment degradation, ABX's strategy is to encourage the urban and rural people to reflect on the connections with nature and community through Community Supported Agriculture. CSA, a concept from Western society, is a good connection for the farmers and consumers to link directly for healthier food and nature as well as fair price for the farmers. In my observation, how this programme of $\mathrm{ABX}$ differs from other agriculture development programmes is: the engagement in globalization market is not the purpose of it; rather, the urban-rural market is built to encourage the consumers to communicate directly with the famers not only on food but also on agriculture-based traditional culture. To produce locally and consume locally are promoted instead of involvement in the globalized market.

Although $\mathrm{ABX}$ is an alternative organization, it has attracted a number of partners with mind-like reflections. In my opinion, it is also a grassroots movement on more localized and peacefully harmonious lives and will make a change. Because $\mathrm{ABX}$ staff has a clear cultural reflection on modern development discourse and practice, they stand in a position to nurture another possibility of development, the grassroots development. The perspective and analysis have a significant role and this is the value of post-development theory.

However, as illustrated above, although the $\mathrm{ABX}$ approach and practice is more like post-development thoughts, it has not dismissed 'development', as proposed by some post-development thinkers, considering its self-description as a 'development organization' (ABX,2006), and rather takes the opportunities to critically discuss what development should be. Actually, development is a fluid and changing word and it has different understandings in diverse cultures and communities.

Furthermore, the local tradition might hybrid with the new approaches. Only focus on the tradition approaches is not necessarily beneficial for the grassroots people. Even for the healthy farming, the overseas experience on organic farming can bring positive elements for the Chinese local farming.

\section{CONCLUSION:}

This paper tries to analyze the roots of post-development theories, first in modern theories and then, post-modern theories. It also provides an in-depth analysis of the strengths and weaknesses of post-development by several empirical examples. Post-development theory is a powerful tool to re-examine the questions of whose 'development' and whether it is relevant for the social majority. The grassroots initiatives and practice are also valuable raised by the post-development theory.

However, practice is even more complicated, full of different actors, power relations and other factors. Post-development theory cannot replace all other development theories; otherwise, it will also become a hegemonic discourse itself. Also, development, as a term and practice, is still fluid and opens to the redefinition and the complete abandonment is not reasonable.

Like Marx said, 'the philosophers have only interpreted the world, in various ways; the point however, is to change it' (in Peet 1999). After the analysis of post-development theory, the practice in the field should take the advantages of the post-development theories' critical thoughts on modernity and the values on the grassroots practice; meanwhile, the localized implementation with diverse theoretic approaches and practical techniques are also necessary.

As the empirical examples presented above refer to particular country contexts, this paper is unable to analyze all the strengths and weaknesses of post-development theories. In addition, I am interested in how the development discourse framed by government and civil society in China and how it is understood by the grassroots people; however, I am limited to the small amount of empirical research available in the field of development in China. Significantly, in the case of China, it shows that development is not necessarily the discourse of Western hegemony; still, the ruling governments continue to use it according to their political and economic wills. This paper, therefore, calls for more ethnographic research of development in countries such as China to encourage more critical thinking and a broader development imaginary. 


\section{REFERENCES}

[1] Alkire,S. \& Deneulin, S.(2009), An Introduction to the Human Development and Capability Approach, London: Earthscan

[2] Brockmann, H., Delhey, J., Welzel, C., \& Yuan. H. ( 2009), 'The China Puzzle: Falling Happiness in a Rising Economy Journal of Happiness Studies', Journal of Happiness Studies , Volume 10, Number 4, 387-405

[3] China Human Development Report, (2005), [online] available from http://www.undp.org.cn/modules.php?op=modload \& name=News\&file= article \& topic $=40 \&$ sid $=228$ (in Chinese) [Accessed 1 January 2011]

[4] Escobar, A. (1995) Encountering Development: The Making and Unmaking of the Third World, Princeton: Princeton University Press.

[5] Gandhi, M. (1997) The Quest of Simplicity. In: Rahnema,M.\& Bawtree,V.eds. Post-development Reader. Dhaka: The University Press, pp.306-307

[6] Hartwick,E. with Peet, R. (1999) Theories of Development, New York: The Guilford Press

[7] Partiff, T. (2002) The End of Development? Modernity, Post-modernity and Development, London: Pluto Press.

[8] Ma Kai (2007), a statement reported by Xinhua Agency on May 4th, 2007, [online] available from http://news.xinhuanet.com/fortune/2007-05/04/content_6056616.htm (in Chinese) [Accessed 6 January 2011]

[9] Parpart, J. (2002), Lessons from the Field: Rethinking Empowerment, Gender and Development from a Post-(Post-?) Development Perspective, In: Saunders,K. eds Feminist Post-development Thought, New York: Zed Books, pp.41-56

[10] Peet, R. with Hartwick,E. (1999) Theories of Development, New York: The Guilford Press

[11] Yang. G (2007) " "New three mountains" produced by "reform": the analysis of education, health and housing system's problems and reasons', Modern China Studies Volume1,2007[online] available from

http://www.usc.cuhk.edu.hk/PaperCollection/Details.aspx?id=6032[acce ssed 28 December 2010]

[12] Zhao, Q.; Hao, B.; Cheng, P. \& Zhou, J (2009), Evaluation report on ABX youth internship programme. unpublished, (Soft copies are distributed amongst the youth training network and no public publication.) (in Chinese)

[13] Zhou,Y.(2007), Forward. In: Zhou.Y., Wu,M., \& Xu,G. eds. Earth is thinking deeply, Hong Kong: Partnerships for Community Development, (in Chinese) 